\title{
Habitat preferences of tigers Panthera tigris in the Sundarbans East Wildlife Sanctuary, Bangladesh, and management recommendations
}

\author{
M. Monirul H. Khan and David J. Chivers
}

\begin{abstract}
We examined the habitat preferences of tigers Panthera tigris in four habitat types in the Sundarbans East Wildlife Sanctuary, Bangladesh. Transect sampling was used to count tiger signs. Mean densities of signs of feeding, resting, defaecation and interaction were significantly different between the four main habitat types (mangrove woodlands, grasslands, sea beaches and transitional areas), whereas movement, scratch-scent-urinal and other signs were not significantly different. This
\end{abstract}

indicates that tigers have habitat preferences for at least some activities. Similar patterns were found in the densities of movement and feeding signs, as well as of resting and defaecation signs, across the four different habitat types. Tigers were found to use soft-barked trees for scratching more often than other types.

Keywords Bangladesh, habitat preference, Panthera tigris, Sundarbans, tiger.

\section{Introduction}

To maintain viable populations large carnivores need extensive areas with adequate prey densities. They are therefore threatened by habitat loss and fragmentation as well as by poaching of themselves and their prey (Woodroffe \& Ginsberg, 1998; Terborgh, 1999; WWF, 1999). The main requirements of the tiger Panthera tigris are a sufficient supply of large prey, enough cover for stalking, and access to water (Sunquist \& Sunquist, 2002). Although tigers are not tied to a particular habitat type or temperature regime and have few ecological constraints that relate to specific habitat requirements (Miquelle et al., 1996), they live at higher densities in areas with a high prey biomass (Sunquist et al., 1999; Sunquist \& Sunquist, 2002). Examining habitat preference by tigers is important in identification of the priority issues of habitat management for long-term conservation of the tiger, its prey and habitat quality. It is known that good quality habitat (i.e. the habitat that supports sufficient populations of large prey species, some vegetation cover so that tigers can ambush, and availability of drinking water) is important for tigers. When good quality habitat is $<50 \%$ of the total habitat tigers no

M. Monirul H. Khan* (Corresponding author) and David J. Chivers Wildlife Research Group, The Anatomy School, University of Cambridge, Downing Street, Cambridge, CB2 3DY, UK. E-mail mmhkhan@hotmail.com

${ }^{*}$ Current address: Department of Zoology, Jahangirnagar University, Savar, Dhaka 1342, Bangladesh.

Received 22 December 2005. Revision requested 8 June 2006. Accepted 3 August 2006. longer breed successfully, and when it is $<30 \%$ tigers no longer occur in an area (Smith et al., 1998).

The ability to detect and analyse animal signs in the wild through non-invasive techniques is becoming an integral part of wildlife research and management, particularly for carnivores that are secretive and costly to capture and study (Leslie, 2001). Mammal signs have various uses (e.g. relative density estimation, presence/ absence surveys, temporal changes in population dynamics) in the study of less visible species (van Dyke et al., 1986; Nichols \& Conroy, 1996; Wemmer et al., 1996) and were used in the study described here to assess the preference of tigers for four different habitat types.

Current management practices to ensure suitable habitat for the tiger and its prey species in the Sundarbans delta of Bangladesh focus primarily on the maintenance of tree cover. This is not based, however, on knowledge of how tigers in the Sundarbans actually utilize the various habitats, including forest, available in this diverse landscape. Our aims were therefore to examine the degree to which tigers use, for a variety of activities, the area's main habitats and to make recommendations, as appropriate, regarding current management practices.

\section{Study area}

The study was conducted in the Sundarbans (Fig. 1), an area of $c .10,000 \mathrm{~km}^{2}$ in the Ganges-Brahmaputra delta of Bangladesh and India. Approximately $60 \%$ of this forest lies in the south-west of Bangladesh and $40 \%$ in the south-east of the Indian state of West Bengal. Monthly mean temperature and relative humidity vary from $23^{\circ} \mathrm{C}$ (during December-January) to $35^{\circ} \mathrm{C}$ (during May-June) 

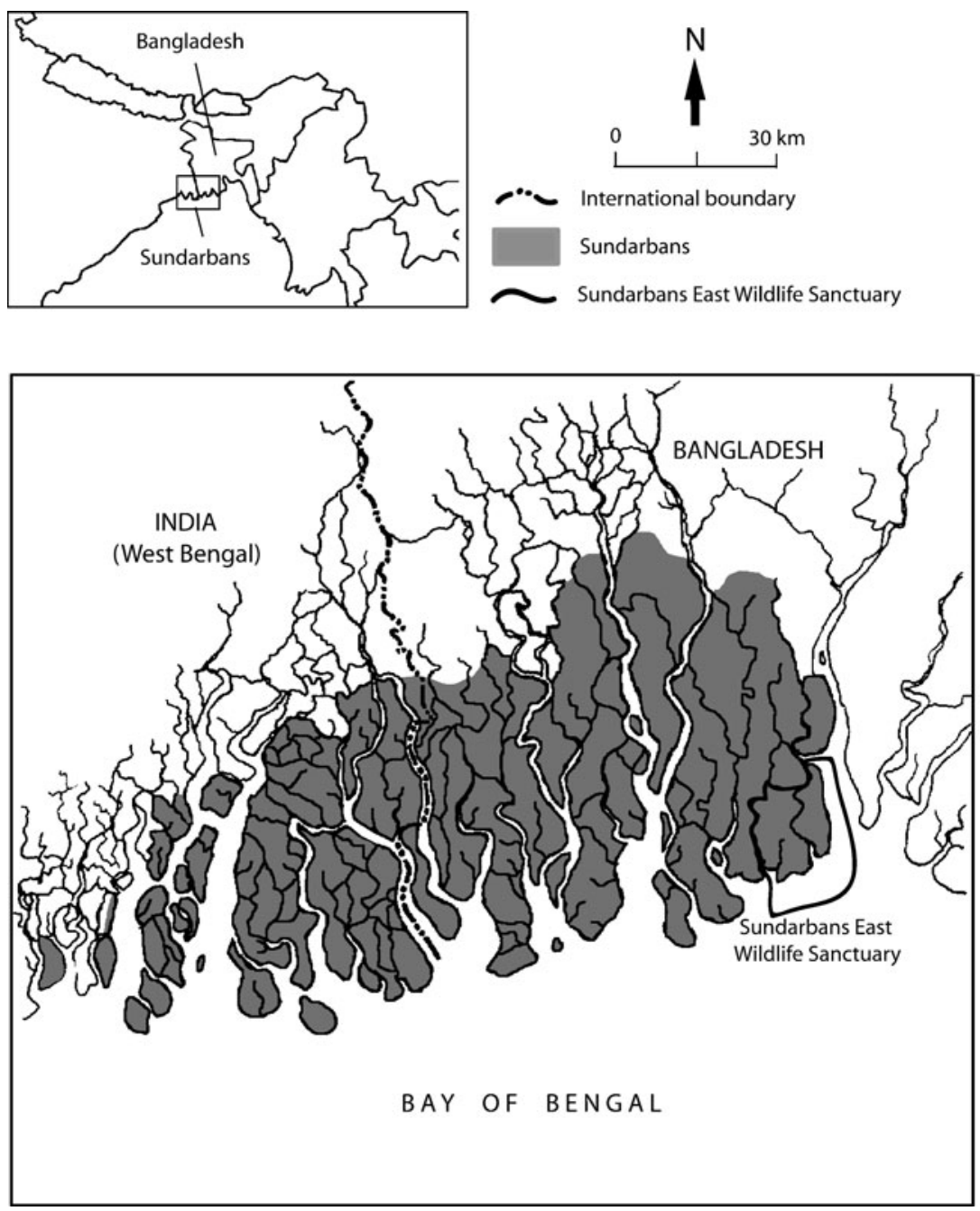

Fig. 1 The Sundarbans of Bangladesh and India showing the study area (Sundarbans East Wildlife Sanctuary). The smaller map shows the location of the main map. and from 70 to $80 \%$, respectively. There are three wildlife sanctuaries in the Bangladesh Sundarbans that together form a UNESCO World Heritage Site. This study was conducted in the Sundarbans East Wildlife Sanctuary, an area of $312 \mathrm{~km}^{2}$ in the south-east that is considered to be the most biodiverse area in the Sundarbans. There are four major habitat types in the Sanctuary: (1) Mangrove woodlands dominated by trees such as Heritiera fomes, Excoecaria agallocha and Sonneratia apetala, comprising c. $70 \%$ of the Sanctuary, and including narrow creeks. (2) Grasslands with species such as Imperata cylindrica, Acrostichum aureum and Myriostachya wightiana, comprising c. $10 \%$ of the area; this habitat type also includes some bare areas and sand dunes. (3) Sea beaches, which are relatively open but narrow sandy strips with sparse reeds and other stunted vegetation, comprising c. $6 \%$ of the area. (4) Transitional areas between mangrove woodlands and grasslands, characterized by having few trees and sometimes sungrass and reeds, comprising c. $14 \%$ of the area.

\section{Methods}

The primary hypothesis was that each of the habitat types is used in proportion to its availability in the study area (Neu et al., 1974; Alldredge \& Ratti, 1986; Otis, 1997). Deviations from expected proportional use are interpreted as evidence of selection. Habitat use is generally considered to be selective if an animal makes choices rather than wandering haphazardly through its environment (Garshelis, 2000). Strip-transect sampling (Burnham et al., 1980; Buckland et al., 1993) was conducted to record the relative abundance of tiger signs in the Sanctuary's four major habitat types. Because the tiger is the only large carnivore in the Sundarbans there is no likelihood of confusing tiger signs with the signs of other animals. Because sample bias can be a potential problem in measuring habitat use based on signs (Garshelis, 2000), sample sizes were large and three assistants continuously accompanied MMHK to assist in observations. Because all transects were narrow ( $5 \mathrm{~m}$ wide) there was 
unlikely to be bias due to visibilities in different habitat types.

A total of $360.2 \mathrm{~km}$ over 276 transects were walked in 18 months (September 2001 to February 2003). Average transect length was $1.3 \mathrm{~km}$ (range $0.5-3.6 \mathrm{~km}$ ) and the monthly average distance covered was $20 \mathrm{~km}$. A global positioning system (GPS; accuracy $\pm 15 \mathrm{~m}$ ) was used to calculate the length of each transect. Sampling effort was uniform for different seasons. Using a stratified sampling design, transects were placed randomly in each of the habitat types. A few areas were unsuitable for survey because of inaccessibility and presence of large rivers. Transects were surveyed at a uniform speed of c. $1.3 \mathrm{~km} \mathrm{~h}^{-1}$ and all types of tiger signs were recorded within a $5 \mathrm{~m}$ wide strip. Transects were maintained in a straight line with the aid of a compass and GPS. Tiger signs recorded were of movement, feeding, resting, defaecation, interaction (with mate/cubs), scratchscent-urinal, and others (hunting, drinking and unidentified activities). Aggregation of the same types of signs produced at the same time were counted as one observation, e.g. many pugmarks along a transect were considered as one movement sign. Because the longevity of signs in the four habitat types was not uniform (mainly because of differences in soil types), signs that were more than $c .10$ days old were discarded. Normally, most of the sign types last at least 10 days in any habitat type in the Sundarbans (M.M.H. Khan, pers. obs.). The age of signs was determined on the basis of observations of the rate of decay of newly produced tiger signs (known to us) and our own footprints in the field in different soil types. To estimate relative abundances of tiger signs (mean number of signs $\mathrm{km}^{-2}$ ), the absolute number of signs for each transect was divided by transect area (length * $5 \mathrm{~m}$ ).

Tiger scratches on trees were recorded to determine which types of trees they prefer to use for this activity. Following Kotwal \& Mishra (1995) notes were taken on the species of trees used, together with the bark type and heights of claw marks from the ground.

\section{Results}

The mean density of all tiger signs combined was highest in mangrove woodlands and lowest on sea beaches (Table 1) but tigers did not exhibit an overall preference for any of the four habitat types (KruskalWallis $H=3.48, \mathrm{df}=3, \mathrm{P}=0.323)$. Means of feeding, resting, defaecation and interaction signs were significantly different between habitat types, indicating that tigers probably have habitat preferences for these activities. The means of movement, scratch-scent-urinal, and other signs were not significantly different between habitat types, indicating that tigers probably have no

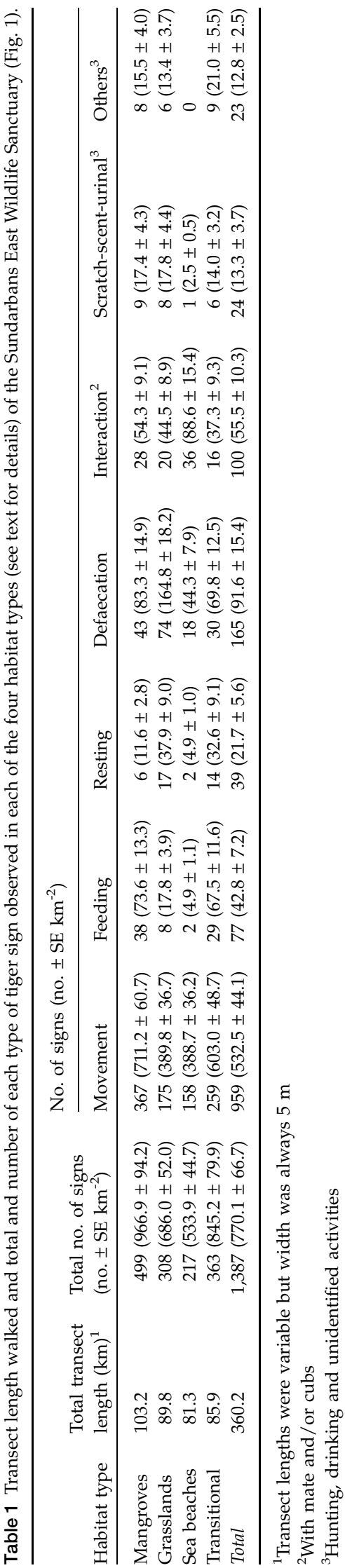


Table 2 Kruskal-Wallis $H$ statistic, degrees of freedom and $P$ value for differences in the density of seven types of tiger sign between the four habitat types (mangrove woodlands, grasslands, sea beaches, transitional areas) of the Sundarbans East Wildlife Sanctuary.

\begin{tabular}{lccr}
\hline & \multicolumn{2}{c}{ Kruskal-Wallis test for means of frequencies } \\
\cline { 2 - 4 } Sign type & $H$ value & df & \multicolumn{1}{c}{$\mathrm{P}$} \\
\hline Movement & 6.72 & 3 & 0.081 \\
Feeding & 11.41 & 3 & 0.010 \\
Resting & 8.66 & 3 & 0.034 \\
Defaecation & 17.45 & 3 & 0.001 \\
Interaction & 28.09 & 3 & 0.001 \\
Scratch-scent-urinal & 0.79 & 3 & 0.852 \\
Others & 3.57 & 3 & 0.312 \\
\hline
\end{tabular}

significant preference for any one habitat type for these activities (Table 2).

Density of movement and feeding signs were highest in mangrove woodlands and transitional areas, resting signs in grasslands and transitional areas, and defaecation signs in grasslands (Table 1). Scats were commonly found in small dry sand dunes and besides footpaths in the grasslands. The density of interaction signs was highest on sea beaches, and scratch-scent-urinal signs in grasslands and mangrove woodlands. The density of other signs was highest in transitional areas.

Scratches were found on three tree species, two of which (Syzygium sp. and Lannea sp.) are relatively softbarked and one (Zizyphus sp.) hard-barked; 13 of the 16 scratches found were on the softer-barked species (Table 3). In general relatively hard-barked trees (e.g. Heritiera fomes, Sonneratia apetala) are more available than soft-barked trees in the Sundarbans. Tigers often repeated scratches on the same individual tree at different times. Scratches were 0.0-2.0 $\mathrm{m}$ off the ground and all were on tree trunks with girths of $c .100 \mathrm{~cm}$. Scratched trees were $0.5-7.0 \mathrm{~km}$ apart.

\section{Discussion}

There are few studies on habitat preference of tigers based on signs because signs are generally difficult to locate in most of the tiger's range. In the Sundarbans, however, tiger signs are relatively easy to find because the ground is soft (Khan, 2004a). The higher density of movement and feeding signs in mangrove woodlands and transitional areas of the Sundarbans East Wildlife Sanctuary is probably because of better cover in these habitats. Most tiger kills were found away from open areas, as in Nagarhole, India, where most tiger attacks $(55 \%)$ on prey, as determined by signs, occurred in moist-deciduous forest habitat that is less open compared to other habitat types (Karanth \& Sunquist, 2000). Reza et al. (2001) examined habitat preference of tigers in the Katka-Kochikhali area $\left(20 \mathrm{~km}^{2}\right)$ in the south-east of the Sanctuary and only $6 \%$ of tracks located were in forest. However, as they did not compare sign frequencies in relation to habitat area there is no strong basis on which to draw conclusions regarding habitat preferences.

The tiger's preference in the Sanctuary for resting in grasslands and transitional areas is probably due to the combination of the drier ground, presence of air flow and less disturbance from humans. Habitat preference for resting and defaecation were similar because tigers often defaecate where they rest. Interaction signs were relatively more common on the sea beaches, and this is probably a nocturnal activity because of human disturbance on the beaches in the daytime. Most of the tiger signs $(69.1 \%)$ were of movement, which is consistent with tigers' need to move frequently for hunting and territory patrolling.

Johnsingh (1983) found that in Bandipur, India, tigers prefer dense vegetation. Our study, however, only weakly supports this, with only movement and feeding signs notably higher in mangrove woodlands than in other habitats. In Kerinci Seblat, Indonesia, Linkie et al. (2003) recorded tiger signs in all the major habitat types, including forested areas, logged areas and open grasslands.

Tigers do not normally kill prey in open habitats such as short grass (Schaller, 1967; Sunquist, 1981; Johnsingh, 1983) and our results from the Sundarbans support this. There were no hunting signs on the sea beaches, probably because it is almost entirely open and because prey density is low in comparison to other habitat types (Khan, 2004b). Although there were hunting signs in the grasslands (probably because the Imperata grasses in the Sundarbans were long enough to provide stalking cover for tigers) the density was lower than in transitional areas and mangrove woodlands. Prey densities are similar in these three habitat types (Khan, 2004b).

Table 3 Tiger scratches found on three tree species in the Sundarbans East Wildlife Sanctuary, with the number of trees used and the height of scratches from ground level.

\begin{tabular}{|c|c|c|c|c|c|}
\hline Tree species & Local name & Family & Bark type & No. of trees & Height from ground $(\mathrm{m})$ \\
\hline Lannea sp. & Kocha, ziga & Anacardiaceae & Very soft & 6 & $0-2.0$ \\
\hline Syzygium sp. & Bon jam & Myrtaceae & Medium soft & 7 & $0.3-2.0$ \\
\hline Zizyphus sp. & Bon boroi & Rhamnaceae & Hard & 3 & $0-1.5$ \\
\hline
\end{tabular}


Both male and female tigers use scratching to mark their territories (Smith et al., 1989). This action perhaps also sharpens the claws by peeling off any thin, loose or desquamated strips of laminae from the surface that are ready to flake off, either on the top of the claw or along the sides and thickened margins (Wynne-Edwards, 1962; Kotwal \& Mishra, 1995). The finding that tigers in the Sundarbans prefer to scratch soft-barked trees agrees with the findings of Kotwal \& Mishra (1995) in Kanha, India, where trees with soft bark were more frequently scratched than those having rough bark, even though the latter were more abundant. However, Kotwal \& Mishra (1995) found that scratches were 0.7-2.7 $\mathrm{m}$ from the ground, higher than recorded in this study. This is probably because the tigers of the Sundarbans are smaller than tigers elsewhere in the Indian sub-continent (Sankhala, 1978; Khan, 2004b).

The findings of this study reveal that tigers use all available habitat types for their various activities in the Sundarbans but that they have some clear habitat preferences for certain activities. Hence, the current management policy for the Sundarbans, which only focuses on the maintenance of woodlands, needs to be modified to ensure the maintenance of the wider landscape as a suitable habitat for tigers. Habitat diversity is also required for the maintenance of the tiger's prey, because different prey species require different habitat types. For example, spotted deer Axis axis feed on grass blades and fallen fruits but wild boar Sus scrofa feed on roots and tubers, which are available in different habitat types. Although the tiger is known to be a habitat generalist (Nowell \& Jackson, 1996) its preference for soft-barked trees is just one example of how different components of a diverse habitat can be useful for its daily life. This again emphasises the importance of conserving the entire landscape, and not only the mangrove woodlands, for the conservation of the tiger.

\section{Acknowledgements}

We gratefully acknowledge support from the Commonwealth Scholarship (UK), WWF Prince Bernhard Scholarship for Nature Conservation (Switzerland), Cambridge Commonwealth Trust (UK), University of Cambridge Foreign Travel Fund, and Selwyn College, University of Cambridge. We also thank the Bangladesh Forest Department for giving permission to work in the Sundarbans East Wildlife Sanctuary and providing local support.

\section{References}

Alldredge, J.R. \& Ratti, J.T. (1986) Comparison of some statistical techniques for analysis of resource selection. Journal of Wildife Management, 50, 157-165.
Buckland, S.T., Anderson, D.R., Burnham, K.P. \& Laake, J.L. (1993) Distance Sampling: Estimating Abundance of Biological Populations. Chapman and Hall, London, UK.

Burnham, K.P., Anderson, D.R. \& Laake, J.L. (1980) Estimation of density from line transect sampling of biological populations. Wildlife Monographs, 72, 1-202.

Garshelis, D.L. (2000) Delusions in habitat evaluation: measuring use, selection, and importance. In Research Techniques in Animal Ecology (eds L. Boitani \& T.K. Fuller), pp. 111-164. Columbia University Press, New York, USA. Johnsingh, A.J.T. (1983) Large mammalian prey-predators in Bandipur. Journal of the Bombay Natural History Society, 80, 1-57.

Karanth, K.U. \& Sunquist, M.E. (2000) Behavioural correlates of predation by tiger (Panthera tigris), leopard (Panthera pardus) and dhole (Cuon alpinus) in Nagarhole, India. Journal of Zoology, London, 250, 255-265.

Khan, M.M.H. (2004a) Mysterious tigers of the Sundarbans. In Tiger: The Ultimate Guide (ed. V. Thapar), pp. 94-98. CDS Books in association with Two Brothers Press, New York, USA.

Khan, M.M.H. (2004b) Ecology and conservation of the Bengal tiger in the Sundarbans mangrove forest of Bangladesh. PhD thesis, University of Cambridge, Cambridge, UK.

Kotwal, P.C. \& Mishra, G.P. (1995) Claw marking on trees by tiger, Panthera tigris (Linn.) in Kanha National Park. Journal of the Bombay Natural History Society, 92, 111-112.

Leslie, E. (2001) Mountain lion-human interactions on the Colorado Plateau: the effects of human use areas on mountain lion movement, behaviour, and activity patterns. In Crossing Boundaries in Park Management: Proceedings of the 11th Conference on Research and Resource Management in Parks and on Public Lands (ed. D. Harmon), pp. 193-196. The George Wright Society, Hancock, USA.

Linkie, M., Martyr, D.J., Holden, J., Yanuar, A., Hartana, A.T., Sugardjito, J. \& Leader-Williams, N. (2003) Habitat destruction and poaching threaten the Sumatran tiger in Kerinci Seblat National Park, Sumatra. Oryx, 37, 41-48.

Miquelle, D.G., Smirnov, E.N., Quigley, H.B., Hornocker, M.G., Nikolaev, I.G. \& Matyushkin, E.N. (1996) Food habits of Amur tigers in Sikhote-Alin Zapovednik and the Russian Far East, and implications for conservation. Journal of Wildlife Research, 1, 138-147.

Neu, C.W., Beyers, C.R. \& Peek, J.M. (1974) A technique for analysis of utilization-availability data. Journal of Wildlife Management, 38, 541-545.

Nichols, J.D. \& Conroy, M.J. (1996) Techniques for estimating abundance and species richness. In Measuring and Monitoring Biological Diversity: Standard Methods for Mammals (eds D.E. Wilson, F.R. Cole, J.D. Nichols, R. Rudran \& M.S. Foster), pp. 177-234. Smithsonian Institute Press, Washington, DC, USA.

Nowell, K. \& Jackson, P. (1996) Wild Cats: Status Survey and Conservation Action Plan. IUCN, Gland, Switzerland.

Otis, D.L. (1997) Analysis of habitat selection studies with multiple patches within cover types. Journal of Wildlife Management, 61, 1016-1022.

Reza, A.H.M.A., Feeroz, M.M. \& Islam, M.A. (2001) Habitat preference of the Bengal tiger, Panthera tigris tigris, in the Sundarbans. Bangladesh Journal of Life Sciences, 13, 215-217. Sankhala, K.S. (1978) Tigers in the wild - their distribution and habitat preferences. In Congress Report, 1st International Symposium on the Management and Breeding of the Tiger, pp. 42-59. Leipzig, Germany. 
Schaller, G.B. (1967). The Deer and the Tiger. University of Chicago Press, Chicago, USA.

Smith, J.L.D., Ahern, S.C. \& McDougal, C. (1998) Landscape analysis of tiger distribution and habitat quality in Nepal. Conservation Biology, 12, 1338-1346.

Smith, J.L.D., McDougal, C. \& Miquelle, D. (1989) Scent marking in free ranging tigers, Panthera tigris. Animal Behaviour, 37, 1-10.

Sunquist, M.E. (1981) Social organization of tigers (Panthera tigris) in Royal Chitwan National Park, Nepal. Smithsonian Contribution to Zoology, 336, 1-98.

Sunquist, M.E., Karanth, K.U. \& Sunquist, F.C. (1999) Ecology, behaviour and resilience of the tiger and its conservation needs. In Riding the Tiger: Tiger Conservation in HumanDominated Landscapes (eds J. Seidensticker, S. Christie \& P. Jackson), pp. 5-18. Cambridge University Press, Cambridge, UK.

Sunquist, M.E. \& Sunquist, F.C. (2002) Wild Cats of the World. University of Chicago Press, Chicago, USA

Terborgh, J. (1999) Requiem for Nature. Island Press, Washington, DC, USA.

van Dyke, F.G., Brock, R.H. \& Shaw, H.G. (1986) Use of road track counts as indices of mountain lion presence. Journal of Wildlife Management, 50, 102-109.

Wemmer, C., Kunz, T.H., Lundie-Jenkins, G. \& Mcshea, W.J. (1996) Mammalian signs. In Measuring and Monitoring
Biological Diversity - Standard Methods for Mammals (eds D.E. Wilson, F.R. Cole, J.D. Nichols, R. Rudran \& M.S. Foster), pp. 157-176. Smithsonian Institute Press, Washington, DC, USA.

Woodroffe, R. \& Ginsberg, J.R. (1998) Edge effects and the extinction of populations inside protected areas. Science, 280, 2126-2128.

WWF (1999) Tigers in the Wild: 1999 WWF Species Status Report. WWF, Gland, Switzerland.

Wynne-Edwards, V. (1962) Animal Dispersion in Relation to Social Behaviour. University of Edinburgh, Edinburgh, UK.

\section{Biographical sketches}

Monirul Khan is a wildlife biologist working in Bangladesh. $\mathrm{He}$ has been involved with a number of wildlife and conservation projects but his main interest is the tiger and other wildlife of the Sundarbans, the largest mangrove forest in the world. David Chivers has been involved over the last 40 years with numerous projects on primates, especially gibbons and now also orang-utans and other wildlife across tropical Asia (Malaysia, Indonesia, Vietnam, Bangladesh, India) and South America (Brazil and Venezuela). 